\title{
Benefits of a Hands-On Introduction to Electrical and Computer Engineering
}

\author{
Frank L. Severance, Maria Suchowski, and Damon A. Miller \\ Western Michigan University
}

\begin{abstract}
This paper presents qualitative and quantitative assessment and evaluation results for an introduction to electrical and computer engineering (ECE) course sponsored by the National Science Foundation (NSF) ${ }^{1}$. This class is centered on construction of a walking robot ${ }^{2}$. Initial results suggest that the following course goals are being met: (1) improving student design and problem solving skills; (2) motivating students and fostering confidence; (3) instilling an appreciation for the importance of prerequisite courses; (4) developing effective team players; (5) improving basic instrumentation and construction skills needed for the practice of ECE; (6) developing a physical intuition for electrical and mechanical systems; (7) clarifying career choices by learning if ECE is a good fit; (8) making students feel like part of the ECE department; and (9) forming long-lasting peer support structures. Assessment results also reinforce the benefits of close instructor involvement, hands-on learning, and project-based courses. Additional details of the course are provided.
\end{abstract}

\section{Note}

This paper is based upon work supported by the National Science Foundation under Grant No. $0088158^{1}$. Any opinions, findings, and conclusions or recommendations expressed in this material are those of the authors and do not necessarily reflect the views of the National Science Foundation.

\section{Introduction}

\section{The Problems}

As discussed in [1,2], our experience is that many students entering electrical and computer engineering (ECE) undergraduate programs lack basic skills and knowledge that were once taken for granted by instructors, e.g. how to use hand tools, how to solder, and the use and function of basic electronic components. Indeed, it seems that the number of students attracted to the ECE discipline by working on radios, automobiles, electronic kits, etc. before entering college is steadily decreasing. Now, many students have never even built the simplest electronic circuit and yet they have chosen to pursue an ECE degree. Thus ECE programs are expected to prepare students from the ground up. The result is that many students often have no passion for ECE and thus lack the motivation needed to complete the difficult pre-engineering curriculum. Indeed, some students discover much too late that engineering is not a good fit for them and still attempt 
to complete the degree given their enormous investment of time and money. The end results are low retention rates and too many underachieving students.

\section{One Approach: A Freshman Level Introduction to Engineering Course}

Introductory engineering courses are one tool to address these problems ${ }^{1,2}$. The Western Michigan University (WMU) Department of Electrical and Computer Engineering has offered such a course (ECE 123 Mobile Robots: An Introduction to Electrical and Computer Engineering) to incoming engineering and science students for four consecutive semesters.

ECE 123 is centered on building Stiquito ${ }^{\mathrm{TM}}$ robots $^{3,4}$. Class meetings consist of a brief lecture followed by extensive laboratory work; students learn by doing. The course is designed to provide a wide overview of engineering, with an emphasis on ECE; an outline is provided in Table 1. Each unit is essentially covered at a pre-calculus "hobbyist" level. The overall goal is to produce a computer controlled Stiquito ${ }^{\mathrm{TM}}$ robot and as time allows an autonomous Stiquito ${ }^{\mathrm{TM}}$ robot with leg movement controlled by an on-board oscillator circuit. Specific course goals will be addressed in the next section.

\begin{tabular}{|c|c|}
\hline unit & material \\
\hline 1 & $\begin{array}{l}\text { course introduction; } \\
\text { laboratory safety; } \\
\text { teamwork; } \\
\text { voltage, current and resistance; } \\
\text { resistive networks; } \\
\text { using a digital multimeter and a power supply }\end{array}$ \\
\hline 2 & capacitors, RC circuits, diodes, and LEDs \\
\hline 3 & $\begin{array}{l}\text { transistors and transistor circuits; } \\
\text { the Darlington array }\end{array}$ \\
\hline 4 & $\begin{array}{l}\text { nitinol wire: characteristics and applications } \\
\text { (nitinol is a flexing wire used to actuate the robot legs) } \\
\text { (dead-weight test and lever experiment) }\end{array}$ \\
\hline 5 & basic Stiquito ${ }^{\mathrm{TM}}$ construction \\
\hline 6 & using Orcad ${ }^{\mathrm{TM}}$ PSpice $^{\mathrm{TM}}$ for DC analysis \\
\hline 7 & $\begin{array}{l}\text { using the signal generator and oscilloscope; } \\
\text { complex waveforms and Orcad }{ }^{\mathrm{TM}} \text { PSpice }^{\mathrm{TM}}\end{array}$ \\
\hline 8 & $\begin{array}{l}\text { RC circuits: simulation work; } \\
\text { RC circuits: experimental work }\end{array}$ \\
\hline 9 & oscillators/555 timer circuit \\
\hline
\end{tabular}

Table 1. ECE 123 Course Outline (continued on next page) 


\begin{tabular}{|c|c|}
\hline 10 & $\begin{array}{l}\text { BASIC programming; } \\
\text { timing loops; } \\
\text { computer interfacing via a parallel port; } \\
\text { constructing a parallel port interface circuit; }\end{array}$ \\
\hline 11 & $\begin{array}{l}\text { using the Stiquito }{ }^{\mathrm{TM}} \text { emulator (Figure 1); } \\
\text { Stiquito }{ }^{\mathrm{TM}} \text { rebuild; }\end{array}$ \\
\hline 12 & $\begin{array}{l}\text { autonomous Stiquito } \\
\text { (completed as time allows) }\end{array}$ \\
\hline 13 & Mobile Robotics Laboratory open house \\
\hline
\end{tabular}

Table 1. ECE 123 Course Outline (continued)

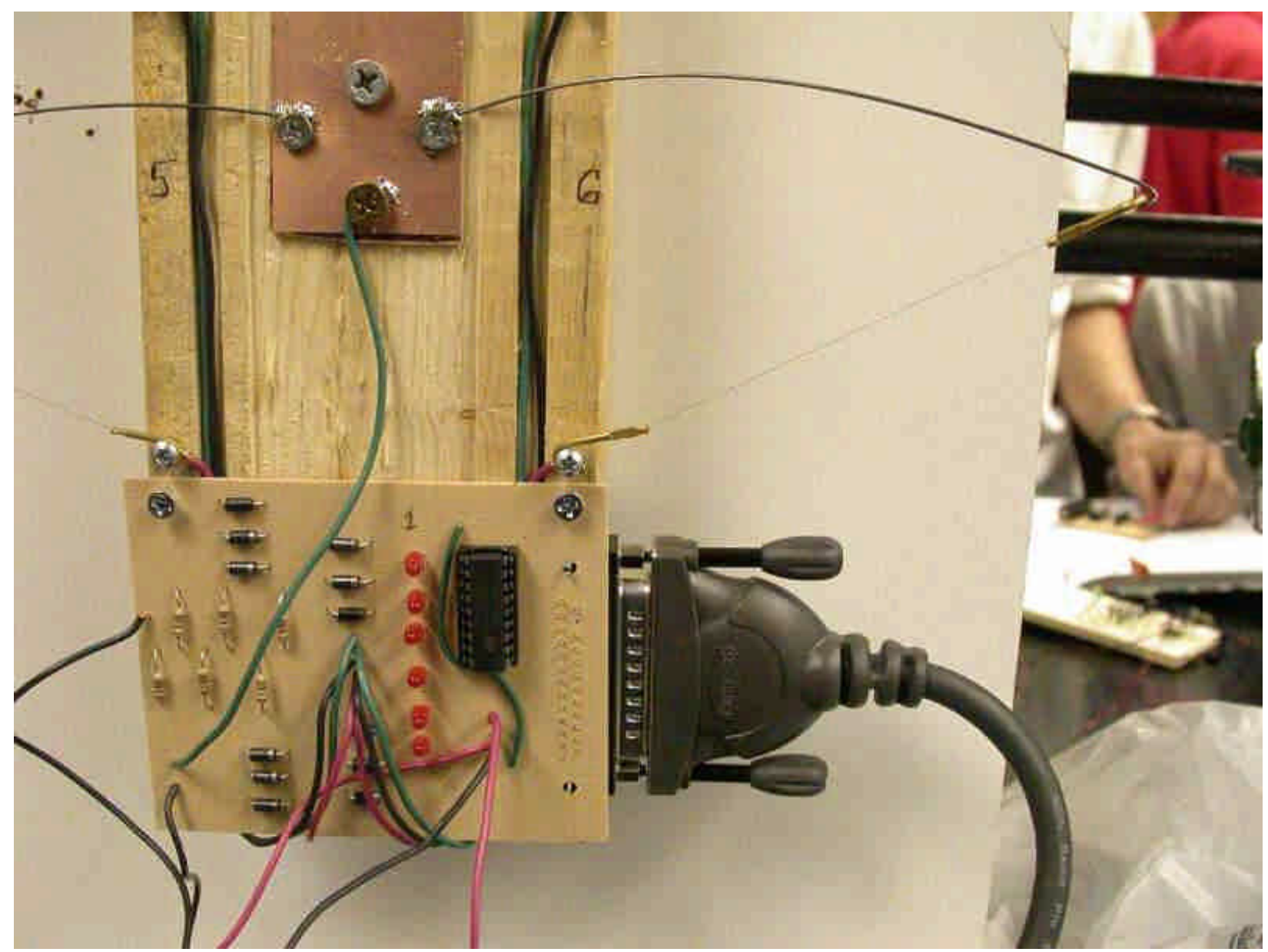

Figure 1. Stiquito ${ }^{\mathrm{TM}}$ Emulator. This unit enables students to design and debug code for their walking robot and is based on parallel port interface circuitry presented in [3]. Only two of the six total legs are shown. 


\section{Preliminary Assessment Results}

\section{Course Objectives and Supporting Evidence}

This section presents the original course goals (verbatim from [1]), previous work that indicates that an introductory engineering course should be able to attain each goal (verbatim from [1]), and evidence from our course (if any) that these goals are being met. Quotes are from students obtained in confidential focus groups conducted by Dr. Suchowski unless otherwise indicated. It should be noted that the results described by Beichner et al. ${ }^{5}$ resulted from using the proposed teaching methodologies in several classes over two semesters as part of an overall integration of the curriculum. The course goals and objectives are as follows.

1. Develop student design and problem solving skills. This type of introductory course has a positive impact on developing these abilities ${ }^{6}$. ECE 123 provides design and problem solving experiences primarily by offering choices during circuit construction and in troubleshooting hardware and software. "When you go through engineering you've got to keep detailed records of your experiments and draw pictures and make conclusions and analyze problems, and that's exactly what this class shows you to do." The class also spurs students to start thinking at a higher "systems" level: "[the class] gets you thinking later. What more could [the robot] do? At least it got me thinking ... how I could make [the robot] so much better now."

2. Motivate students and foster confidence. Our "new, team-taught, interdisciplinary, design-oriented, introduction to engineering course ... has proven to be a very successful motivational experience..." 7 . Beichner et al. found that "student satisfaction and confidence rates were remarkably high" ${ }^{5}$. ECE 123 provides students with a sense of accomplishment that provides both motivation and confidence. "We have something physical to show what we did. This is what I did. I actually made something. This is my lab. I made this." One student referred to the course as "kind of confidence booster." Another student noted "I've got a basic understanding now of what's going on and what to do." This is precisely the goal of the course! Some students were however intimidated by the breadth of the course, wondering if this is an introductory course, what comes next?

3. Instill an appreciation for the importance of prerequisite courses. This type of course "provides a framework for later courses in a traditional curriculum" ${ }^{8}$. One student noted "this class is probably what kept me in engineering because I feel that I have something to look forward to as far as the technical classes down the road." This should result in students better focused on their pre-engineering studies.

4. Develop effective team players. Being able to function on a team is an essential characteristic of successful engineers; Paskusz ${ }^{9}$ notes that as a result of a design based introductory course students "have learned to function effectively on design teams." The course experiments are challenging and often require student teams to extensively cooperate with one another and share information. Many students cited the rewarding

Proceedings of the 2003 American Society for Engineering Education Annual Conference \& Exposition Copyright (C) 2003, American Society for Engineering Education 
experience of working as a group: "it isn't like just working in teams. It's the whole class working together to try to get something done." "Everyone helped everyone." The course is providing experience with the essential engineering skill of working with others: "I think it's important to learn to work with other people, especially people that like to do the same thing you do."

\section{Improve basic instrumentation and construction skills needed for the practice of}

ECE. The course is focused on designing, debugging, and building walking robots using concepts from both electrical and mechanical engineering ${ }^{3}$. The entire course is centered on the laboratory and the construction of the robot. This includes using hand tools, soldering, using test equipment, building circuits on breadboards and on printed circuit boards, computer programming, etc. "They [the instructors] use the Stiquito ${ }^{\mathrm{TM}}$, the robot building, as more of an engine to teach us other stuff, like basic circuitry, various equipment and how to use it, with basic computer programming ... all kinds of little things, making it well rounded."

6. Develop a physical intuition for electrical and mechanical systems, an essential ingredient of effective learning ${ }^{10}$. Many engineering students begin their studies without ever having worked with their hands or knowing even the basic building blocks of their trade. This course provides hands-on experience with a wide breadth of electrical and computer engineering components and tools as well as some basic mechanical engineering concepts. "... When we started out I had no idea what any of the parts were, resistors, transistors ... and then we got into building the Stiquito ${ }^{\mathrm{TM}}$, which was kind of mechanical and now we're into writing a computer program that uses the computer ports to power [control] the legs." "The workplace [environment] and the physical hands-on experience are the best things about the class."

7. Clarify career choices. Introductory courses enable students to evaluate their career choice at an early date ${ }^{7}$. Perhaps the single greatest impact of ECE 123 has been to help students to decide early on if engineering is a good fit. The course has helped students to choose exactly which major suits them best. This includes strengthening an existing resolve to become electrical or computer engineers ("It's just helped me to reinforce that awareness that I'm doing what I wanted."), causing engineering students to switch from a non-ECE major to ECE, and attracting students who had not previously considered engineering as a career to switch to an ECE major. For example, one student related that "sometimes it was hard, and we talk, and I think I really don't want to be an engineer, and yet I really do because of this class. I know what it's about. I enjoy doing this stuff that we do and it makes me want to be an engineer more. Just from this class."

Equally important is that for some students this course clearly showed that engineering was not for them. "I was thinking about engineering a lot, not really knowing a lot about it, but now that I've taken this class, I think that this was a really good class, but now I know that I'm not going to do engineering ... and I don't think the other engineering classes towards the major would really show me that engineering isn't really what I'm into, and this class was good, if that makes any sense." Another student noted "a different 
course wouldn't have helped with the decision. Not at all. You can read a textbook and it is this and that and then you actually go to do it and this isn't bending the right way or this is a lot smaller than I thought, you just run into all kinds of real problems. I decided it's not something I want to continue ... It's great for people who are either a little bit sure or a little unsure."

These outcomes are demonstrated in the quantitative results of Table 2 that are based on responses of 31 students who participated in one of the four focus groups held at the end of the ECE 123 course in the Fall 2001 and Winter 2002 term. Of the 31 student respondents, 8 volunteered the opinion that the course strengthened their resolve to be engineers or helped to reinforce their original engineering goal. These students were all electrical or computer engineering majors. In addition, four of ten students who said that they had been interested in other engineering fields said that participating in the course had now influenced them towards the study electrical or computer engineering. Two additional students who had been undecided about their majors said that the course had helped them to decide that electrical or computer engineering was now their intended course of study. On the other hand, four students (3 computer engineering and one undecided) said that the course was a good one but clearly showed them that engineering was not a good fit.

8. Make students "feel at home in the ... department" ${ }^{9}$. A pre/post questionnaire ${ }^{2}$ indicates that students now feel they have friends in the electrical engineering department. This is not surprising given the close support they are provided during class by both faculty and student assistants.

9. Break down ethnic and gender divisions. Beichner et al. in particular noted a "lowering of racial barriers" 5 . There is insufficient evidence at this point to address this objective.

10. Form long-lasting peer support structures. According to [5] "the most important finding from our analysis of the qualitative data is the central role that socialization played in the success of students." The ECE 123 assessment described an increase in camaraderie among class members. "I've gotten to know a lot of people, just because you're working so close; you're working together."

11. Improve student performance in subsequent courses. This will be a consequence of achieving the first seven goals. This effect has been noted in $[5,11]$. The wide breadth of topics covered both theoretically and experimentally in this course should have a positive impact on subsequent courses; further assessment results are required here. "Everything that you're learning in here you're going to need for another class, any kind of engineering." 


\begin{tabular}{|l|l|l|l|l|l|}
\hline \multicolumn{1}{|c|}{ Before ECE 123 } & \multicolumn{5}{|c|}{ After ECE 123 } \\
\hline Intended Major & $\begin{array}{l}\text { Electrical } \\
\text { Eng. }\end{array}$ & $\begin{array}{l}\text { Computer } \\
\text { Eng. } \\
\text { Computer } \\
\text { Science }\end{array}$ & $\begin{array}{l}\text { Other } \\
\text { Eng. }\end{array}$ & Undecided & $\begin{array}{l}\text { Other } \\
\text { Non-Eng. }\end{array}$ \\
\hline Electrical Eng. (7) & $7\left(4^{*}\right)$ & $8\left(4^{*}\right)$ & & & 3 \\
\hline $\begin{array}{l}\text { Computer Eng. } \\
\text { Computer Science } \\
(11)\end{array}$ & 2 & 2 & 6 & & 1 \\
\hline $\begin{array}{l}\text { Other Eng. (10) } \\
\text { Undecided (3) }\end{array}$ & 1 & 1 & & \\
\hline
\end{tabular}

Table 2. Matrix of Intended Majors Before and After Electing ECE 123

12. Increase retention rates. Beichner et al. "noted substantial increases in retention and success rates for [underrepresented] groups" after using many of the teaching methods used in this project ${ }^{5}$. Finelli ${ }^{11}$ agrees that this increase is one outcome of exposing students to teamwork and projects early in their academic career, citing [12]. Additionally, the "evidence does indicate that all students may benefit when teamwork and design are effectively incorporated into a first-term freshman course" ${ }^{11}$. Reference [13] notes that "... the overwhelming impression of faculty teaching this [introductory] class and subsequent classes and labs [is] that the goals of retention and improved learning have been achieved."

As noted, some students have switched from engineering to other majors after determining that engineering was not a good fit; however, the students that continue should be better prepared and motivated. Retention rates among those students completing this course and continuing in engineering should increase since students who opt out of engineering after this course would likely have left later in their studies. There is insufficient data at this point in the project to support this conjecture.

Proceedings of the 2003 American Society for Engineering Education Annual Conference \& Exposition Copyright (C) 2003, American Society for Engineering Education 


\section{Other Observations}

The focus groups also revealed these course benefits.

1. Benefits of close instructor involvement. Having faculty intensively involved with freshman has had a positive impact on student motivation and to their sense of belonging to the ECE department. "Dr. Severance brings in his graduate students and Dr. Miller all the time ... and they answer questions ... it's nice ... we do things spontaneously." Students clearly appreciate the genuine interest of the instructors. "In other classes, if you're a little behind, they won't let you finish. When time's up, time's up, you know, so you just don't care. In this if you're not done you come in later. They want you to finish."

2. Benefits of hands-on learning. Learning by doing is an essential component of engineering education. The assessment results provide further reinforcement of this fact and the focus groups identified the value of hands-on work to reinforce the lecture "We have a lecture and go straight to lab ... the applied stuff follows exactly." "With this [course], we do a lecture and we go right to lab about that lecture so we learn." "You learn the theory. You learn how to do it on paper. And then you apply it to the lab and you actually do it in real life ... all in one room."

3. Benefits of project centered courses. As opposed to classes where students do not understand why they are conducting an experiment, this course is focused on the end goal of producing a robot. "You know why you're doing something." "With my other lab, you do what you do today and you're done with that lab. You don't deal with that lab ever again. You go onto a whole new subject. This one you keep building." This benefit was also observed in [7].

\section{General Student Comments}

General comments of the course included: "I've learned more in this class than any other class I've had this semester" and "I've never had a class where you actually learned so many things that you didn't know anything about and actually applied them all."

These results are positive indications that the course is meeting most of its goals; the exact degree of success will be determined by the final assessment and evaluation results.

\section{Future Work and Conclusions}

The assessment and evaluation effort is continuing and final results will be presented in a future paper. This will include further sample points for a pre-course and post-course attitude survey (as presented in [2]) and results for a pre-course and post-course skills test. Evaluation of the course objectives: 3 (instill an appreciation for the importance of prerequisite courses), 11 (improve student performance in subsequent courses), and 12 (increase retention rates) in particular will require examination of student performance over the next several years.

Proceedings of the 2003 American Society for Engineering Education Annual Conference \& Exposition

Copyright (C) 2003, American Society for Engineering Education 
Preliminary results as presented here suggest that ECE 123 is meeting its primary objectives and reinforce the proven value of introductory engineering courses.

\section{References}

1. D. A. Miller, M. Z. Atashbar, F. L. Severance, and R. Tanner, "Walking before running: Filling the freshman engineering gap by building mobile Stiquito ${ }^{\mathrm{TM}}$ robots," proposal to the National Science Foundation Course, Curriculum, and Laboratory Improvement Program.

2. M. Z. Atashbar, D. A. Miller, F. Severance, R. Tanner, and M. Suchowski, "Bridging the freshman engineering gap by building mobile robots," in Proc. of the 2002 American Society for Engineering Education Annual Conference, (Montreal, Quebec), June 16-19, 2002.

3. J. M. Conrad and J. Mills, Stiquito ${ }^{T M}$ for beginners: An introduction to robotics, IEEE Computer Society, Los Alamitos, California, 1999

4. J. M. Conrad and J. J. Brickley, Jr., "Using Stiquito in an introduction to engineering skills and design course," in Proceedings of the Frontiers in Education 27th Annual Conference\}, vol. 3, (Pittsburgh, PA), pp. 1212-14, November 5-8, 1997.

5. R. Beichner, L. Bernold, E. Burniston, P. Dail, R. Felder, J. Gastineau, M. Gjertsen, and J. Risely, "Case study of the physics component of an integrated curriculum," American Journal of Physics, vol. 67, pp. S16-S24, July 1999.

6. J. Schmidt, C. Yang, O. Wilson, and G. Zhang, "Assessment of the teaching-learning effectiveness of a freshman design course," in Proceedings of the 29th ASEE/IEEE Frontiers in Education Conference, (San Juan, Puerto Rico), pp. 1-6 in session 13b1, November 10-13, 1999.

7. C. F. Yokomoto, M. E. Rizkalla, C. L. O'Loughlin, and N. Lamm, "A successful motivational design experience using attached learning," in Proceedings of the 28th Annual Frontiers in Education Conference\}, vol. 1, (Tempe, AZ), pp. 493-9, November 4-7, 1998.

8. S. L. Wood, "A concept oriented introductory course utilizing multimedia presentations and group laboratory experience," in Proceedings of the 28th Annual Frontiers in Education Conference, vol. 2, (Tempe, AZ), pp. 824-9, November 4-7, 1998.

9. G. F. Paskusz, "A design based introduction to electrical engineering," in Proceedings of the 28th Annual Frontiers in Education Conference\}, vol. 2, (Tempe, AZ), pp. 955--7, November 1998.

10. D. W. Johnson, R. T. Johnson, and K. A. Smith, "Active learning: Cooperation in the college classroom," in ASHE-EIRC Report on Higher Education, (Washington, D.C.), 1991.

11. C. J. Finelli, "A team-oriented, project-based freshman engineering course: Benefits of early exposure," in Proceedings of the 29th ASEE/IEEE Frontiers in Education Conference, (San Juan, Puerto Rico), pp. 6-30 in session 11a2, November 10-13, 1999.

12. M. R. Anderson-Rowland, "The effect of course sequence on the retention of freshmen engineering students: When should the intro engineering course be offered?," in Proceedings of the 28th Annual Frontiers in Education Conference, vol. 1, (Tempe, AZ), pp. 252-7, November 4-7, 1998.

13. D. R. Scott and J. M. Hatfield, "An application-oriented freshman-level electrical circuits course," in Proceedings of the 28th Annual Frontiers in Education Conference, vol. 2, (Tempe, AZ), pp. 831-5, November 4-7, 1998.

Proceedings of the 2003 American Society for Engineering Education Annual Conference \& Exposition Copyright $\left({ }_{0}\right.$ 2003, American Society for Engineering Education 


\section{Biographical Information}

FRANK L. SEVERANCE is an Associate Professor in the Department of Electrical and Computer Engineering. His research interests include mobile robots and system modeling and simulation. He may be contacted at frank.severance@wmich.edu.

MARIA SUCHOWSKI is a contract consultant to Western Michigan University for the evaluation and assessment of the ECE 123 course. Her research interests include educational evaluation and measurement. She may be contacted atmsuchowski@hotmail.com.

DAMON A. MILLER is an Assistant Professor of Electrical and Computer Engineering. His research interests include nonlinear circuits and systems, neural networks, and engineering education. Further information about Dr. Miller and the ECE 123 course is available at "homepages.wmich.edu/ miller". 